\title{
The effect of ethical values on transformational leadership and ethical climate in organisations
}

\author{
A.S. Engelbrecht*, A.S. van Aswegen and C.C. Theron \\ Department of Industrial Psychology, University of Stellenbosch, \\ Private Bag X1, Stellenbosch 7602, Republic of South Africa \\ ase@sun.ac.za
}

Received July 2004

\begin{abstract}
Ethical leaders are ultimately responsible for developing a strong and sustainable ethical climate in organisations. Ethical values and the ability to influence followers to internalise these values have become prerequisites for effective leadership in modern organisations. Although ethics, leadership, and values have received much attention, there has been little coordinated effort to integrate transformational leadership with ethical climate and ethical values. The aim of this study was to develop and validate a theoretical model to explain the structural relationships between these variables in the South African business context. The results revealed that altruism influences transformational leadership positively, and that transformational leadership in turn has a positive effect on ethical climate. Some support was also found for the proposition that integrity moderates the effect of transformational leadership on ethical climate.
\end{abstract}

*To whom all correspondence should be addressed.

\section{Introduction}

Since business organisations present a principal domain for developing social norms and values, creating an ethical work climate can have broader implications for moral conduct across the social spectrum (Cohen, 1993). An ethical climate involves important consequences for organisations, including the legitimisation of managerial actions, improved trust, consistency of standards and quality of products, greater organisational commitment and increased effectiveness due to strengthened organisational culture (Carlson \& Perrewe, 1995; Dickson, Smith, Grojean \& Ehrhart, 2001).

Scholars and practitioners agree that the values and practices of top management are crucial in setting the ethical climate of an organisation (Cohen, 1993). Ethical leadership is known to contribute to employee commitment and satisfaction, as well as to attract and retain the best employees (Trevino, Hartman \& Brown, 2000). Transformational leadership, in particular, has been shown to be related to a number of positive subordinate outcomes, including trust and respect for the leader, procedural justice and unit performance (Bass \& Avolio, 1994; Craig \& Gustafson, 1998; Krafft, Engelbrecht \& Theron, 2004). Evidence has suggested that transformational leaders adhere to high ethical standards and behave in ways that are congruent with these standards (Parry \& Proctor-Thomson, 2002).

Business ethics, leadership and values have emerged as important issues in society during the past decade and are considered vital to business success in the long term. Although these constructs have received much attention, little co-ordinated effort has been made to integrate transformational leadership with ethical climate and ethical values. No previous study of this nature has been conducted in the South African context, which is characterised by constant change and turbulence. With unethical behaviour and corruption prevailing in organisations, it has become necessary to find solutions to this problem to improve the current situation (Malan \& Smit, 2001; Rossouw, 1997; Van Niekerk, 2003). It is believed that leaders play a key role in determining the ethical climate of an organisation. This research attempts to present one of the many conceptual relationships between leadership behaviour and the resultant ethical behaviour in organisations.

An ethical climate can only be attained when the factors that affect an ethical climate, are understood. Therefore the specific aim of this study was to develop and test a model that would unravel the factors that determine an ethical climate through the exploration of the ethical values of transformational leaders (see Figure 1). Altruism and integrity, in particular, are recognised in the literature as core ethical values of transformational leaders (Ciulla, 1996; Engelbrecht, 2002; Kanungo \& Mendonca, 1996). The main goal of this study was to establish whether there was a relationship between transformational leadership and the development of an ethical climate in organisations. One of the objectives of this study was to establish whether there was a direct relationship between altruism and transformational leadership. Another objective was to establish whether integrity had a moderating effect on the relationship between transformational leadership and ethical climate. 


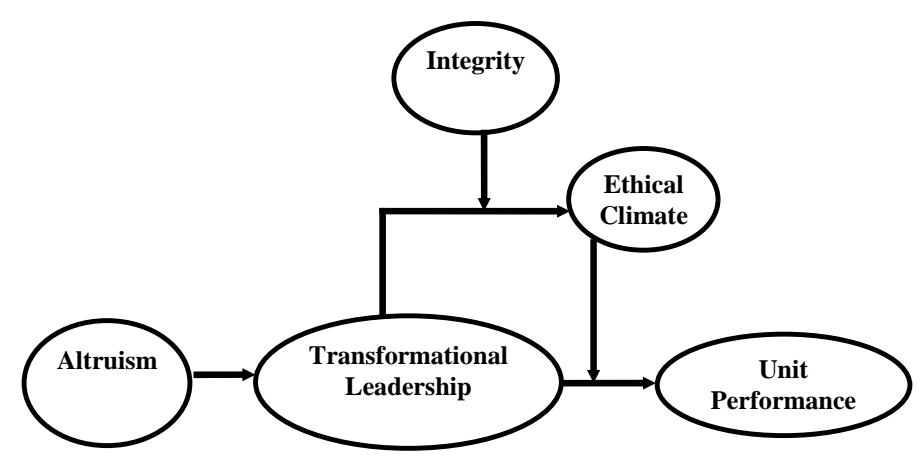

Figure 1: A theoretical model of the structural relationships between transformational leadership and ethical climate.

\section{Altruism and transformational leadership}

Altruism is recognised in the literature as a core ethical value of transformational leadership (Ciulla, 1996; Engelbrecht, 2002; Kanungo \& Mendonca, 1996). Altruism has been defined as behaviour intended to benefit others without the expectation of an external reward (Kanungo \& Mendonca, 1996:37). Organisational leaders are truly effective when they are motivated by a genuine concern for other people and when their actions are guided by the criteria of "the benefit to others even if it results in some cost to self" (Kanungo \& Mendonca, 1996:37). Altruistic leadership encourages and inspires people to use their human potential and energy in the best way, so that the organisation's purpose may be achieved (Malan \& Smit, 2001).

The transformational leader's influence on his/her followers is gained through the fact that followers perceive the leader's efforts to be selfless and the intent to be altruistic (Kanungo \& Mendonca, 1996). The altruistic leader not only tries to live according to the principles of integrity, service and promotion of the broader interest, but also according to the principles of transformational leadership, where the focus is on transforming the followers in the same way (Malan \& Smit, 2001).

A transformational leader sacrifices own gain so that others may gain, and motivates followers to transcend their own self-interests in the interest of their organisation (Bass \& Avolio, Conger \& Kanungo and Sashkin, cited in Engelbrecht, 2001). The transformational leader aligns the altruistic values of his/her followers with his/her own, resulting in altruistic value congruence, which leads to higher levels of trust based relationships between leaders and followers (Engelbrecht, 2002). Thus, in order to gain trust, build commitment to his/her goals, and achieve exceptional levels of performance, the transformational leader should be perceived as sharing altruistic values (Engelbrecht, 2002). Engelbrecht (2002) posits that, in order to foster ethical transformational leader behaviour, altruistic values such as collectivism, benevolence and equity must exceed trading values such as achievement and advancement. This is consistent with research by Kanungo \& Mendonca (1996) who argue that altruism should be a central aspect of any ethical climate.
From the above assumptions and findings, the following can be postulated:

\section{Hypothesis 1:}

Altruism has a positive influence on transformational leadership.

\section{Transformational leadership and ethical climate}

Ethical climate has been defined as the moral atmosphere of a social system characterised by shared perceptions of right and wrong, as well as assumptions about how moral concerns should be addressed. It is the way in which an organisation handles issues such as responsibility, accountability, communication, regulation, equity, trust and the welfare of constituents (Victor \& Cullen, 1988).

Climate formation starts with the leaders of the organisation - founders and early leaders bring to the organisation their individual values which play a pivotal role in determining the organisation's strategy, structure, climate and culture (Dickson et al., 2001). The transformational leadership style lends itself well to the creation of an ethical climate (Carlson \& Perrewe, 1995). Transformational leadership not only involves the moral elevation of individual followers, but also collective efforts to accomplish change. During the process, both leader and follower will be transformed. They consider not only what is good for themselves, but also what benefits their organisation, community and nation (Yukl, 2002).

The transformational leader is a role model displaying the behaviours required to reinforce ethical behaviour. Leaders that take a strong personal stand on the need for ethical behaviour will contribute to an ethical climate, as characteristics of top level executives appear to be related to organisational outcomes (Matthews, 1987). Organisational ethics is cultivated when top management gives strategic importance to the construction and maintenance of commitment to an organisational system of ethics. This includes leadership by moral example to guide and align all ethics-centred initiatives (Schminke, 1998).

Outcomes such as dramatic changes in the organisation's culture and strategies are often the result of transformational leadership (Carlson \& Perrewe, 1995). By appealing to the moral values of the individual, transformational leadership involves a process that allows the leader's vision of an ethical culture to filter throughout the organisation.

Thus, the following hypothesis can be postulated:

Hypothesis 2:

Transformational leadership has a direct, positive influence on ethical climate.

\section{Integrity and transformational leadership}

Although equitable systems and structures are important in the development of the organisation's ethical climate, it is the leader's personal conduct that determines the effectiveness of codes, policies, procedures and support structures. An organisation's ethical climate should be a 
natural overflow of the leader's commitment to ethical principles and values expressed in a daily struggle to live by such principles and values (Kanungo \& Mendonca, 1996). The leader's consistency with regard to decisions and behaviour in his or her lifestyle will reveal him or her as dependable and trustworthy (Engelbrecht \& Cloete, 2000), as well as give meaning and importance to otherwise routine activities of the workplace. Thus the leader will be seen to have integrity. The resulting ethical environment will then truly reflect the soul of the organisation, as well as enable members to internalise values, providing a firm foundation for ethical behaviour (Kanungo \& Mendonca, 1996).

Integrity lies at the heart of leadership. According to the Oxford English Dictionary the root meaning of the term integrity is wholeness, which suggests coherence between principle and action, rightness, and a sense of moral soundness (McFall, 1987). It implies a character of uncorrupted virtue, honesty and sincerity (Montefiore \& Vines, 1999). Leaders with integrity will aspire to consistency and coherence in what they believe, how they lead, and the type of organisations they want to build (Badaracco \& Ellsworth, 1991). This consistency of personal beliefs and values in daily working behaviour and organisational aims is referred to as integrity.

Integrity is presented as a core value of transformational leadership, as no organisation can function to its capacity unless its people can rely on the promises and commitments of their leaders (Hesselbein, Goldsmith \& Beckhard, 1996). Leaders have to keep their promises to the people they lead, even if it involves personal risks and sacrifices.

Ethical integrity is an important aspect of leadership leadership skills alone are not sufficient; these skills must be coupled with integrity and ethical behaviour (Carlson \& Perrewe, 1995). To be optimally effective, leaders should be perceived by followers as displaying a level of integrity consistent with their followers' expectations (Craig \& Gustafson, 1998).

Transformational leaders work on a basis of personal values such as integrity and justice and believe that it is the best method for instilling ethical behaviour in organisations (Carlson \& Perrewe, 1995). However, although integrity, justice and ethics are shown to be conceptually related to transformational leadership in the literature, the link between them has been given little consideration in empirical research (Parry \& Proctor-Thomson, 2002). Integrity and trustworthiness have been identified as important aspects of the highly effective transformational leadership style (Craig \& Gustafson, 1998; Engelbrecht, 2001).

Hence, it can be postulated that:

\section{Hypothesis 3:}

The interaction between integrity and transformational leadership produces variance in ethical climate not attributable to the main effect of transformational leadership.

\section{Method}

Sample

The target population was defined as medium to large companies operating in the Western Cape, South Africa. Non-probability sampling, more specifically convenience sampling, was used in this study. A total of 360 questionnaires were sent out and a total of 203 completed questionnaires were returned. This represents a response rate of $56 \%$.

The organisations that were investigated varied in terms of the industry sector in which they were active, and ranged from electricity manufacturing plants to insurance firms, and from retailers and banks to accounting and auditing firms. More males $(61,5 \%)$ than females responded to the questionnaire. Ethnically, the sample consisted of both white and black $(35,8 \%)$ respondents. Of the respondents, $58,8 \%$ were working in non-managerial positions, $19,1 \%$ and $15,6 \%$ were employed in lower-level and middle-level management positions, respectively. Only $13(6,5 \%)$ upperlevel managers responded to the questionnaire. The average age of employees was 32,2 years and the average working experience 12,4 years.

\section{Measuring Instruments}

The research utilised a combined questionnaire consisting of five sections. Section A was designed to give an indication of the demographics of the participants. Section B measured transformational leadership, based on Bass and Avolio's (1995) Multifactor Leadership Questionnaire (MLQ). Item analyses by Krafft et al. (2004:21) produced good reliabilities for the four transformational leadership sub-scales $(0,72 \leq \alpha \leq 0,84)$. Through confirmatory factor analyses, uni-dimensionality was assured on all four transformational leadership sub-scales, and factors loaded satisfactorily $(0,57<\lambda<0,83)$ on the postulated dimensions (Krafft et al., 2004). A meta-analysis of the MLQ literature was conducted, and it was found that the transformational leadership scales were reliable and possessed good predictive validity (Lowe, Kroeck \& Sivasubramaniam, 1996).

Section C was compiled in accordance with Victor \& Cullen's Ethical Climate Questionnaire (ECQ), which measured respondents' perceptions of the ethical dimensions of their work climate. The measures of each sub-climate have satisfactory reliabilities $(0,65 \leq \alpha \leq 0,82)$ (Victor \& Cullen, 1987). From their analysis, it was concluded that the Ethical Climate Questionnaire scales were adequate for subsequent investigative research (Weber, 1995).

Section D measured altruism, based on Langley's (1992) Value Scale. The reliability coefficient obtained by Langley for the altruism subscale was 0.86 , and construct validity was evidenced by the nature of the factor structure (Langley, 1992).

Section E measured integrity using Butler's Conditions of Trust Inventory (Engelbrecht \& Cloete, 2000). Items measuring integrity (honesty), consistency and promise 
fulfilment were used to form a 12-item scale. Butler reported satisfactory internal consistency for the subscales of integrity $(\alpha=0,92)$, consistency $(\alpha=0,87)$ and promise fulfilment $(\alpha=0,96)$ (Engelbrecht $\&$ Cloete, 2000).

\section{Results and discussion}

The theoretical model derived from the literature study hypothesises specific structural relationships between the latent variables (see Figure 1). The results of the statistical analyses aimed at testing the stated hypotheses are reported below. The treatment of missing values will be discussed first, followed by detailed results of the dimensionality analyses and item analyses that were performed to establish the psychometric soundness of the indicator variables used to represent the various latent variables. The results of the correlation and regression analyses will then be presented.

\section{Missing values}

Various options to solve the missing value problem were explored. The classical treatment of the missing value problem through list-wise deletion of cases would have reduced the sample size to 162 . It was therefore decided to use imputation as a method to solve the problem. The PRELIS programme (Jöreskog \& Sörbom, 1996) was used to impute missing values. After imputation, 200 cases with observations on all measured items remained in the validation sample.

\section{Dimensionality analysis}

Dimensionality analyses were conducted with the use of SPSS (SPSS, 1990). Unrestricted principal component analyses with Varimax rotation were performed on each subscale of the questionnaire with the objective of confirming the uni-dimensionality of each subscale and to remove items with insufficient factor loadings and/or split heterogeneous subscales into two or more homogenous subsets of items, if necessary.

In the case of the MLQ, all four of the transformational leadership subscales passed the unidimensionality test. All factors had satisfactory factor loadings $(0,50<\lambda<0,86)$ on the dimensions they were originally allocated to.

Only one of the four subscales of the Ethical Climate Questionnaire failed the uni-dimensionality test. The problem could, moreover, not be solved through the deletion of single wayward items. The Caring Climate Subscale presented a clear two-factor orthogonal factor structure. All items allocated to the subdivided subscales loaded satisfactorily $(0,54<\lambda<0,87)$ on a single factor.

The Altruism scale passed the unidimensionality test. All items comprising the scale displayed highly satisfactory factor loadings on the first principal component $(0,87<\lambda<$ $0,93)$.

The Integrity Scale failed the unidimensionality test. The problem could, again, not be solved through the deletion of single wayward items. The integrity scale was subsequently subdivided into two orthogonal uni-dimensional subscales.
All items allocated to the subdivided subscales loaded satisfactorily $(0,48<\lambda<0,91)$ on a single factor.

\section{Item analysis}

Item analysis was performed through the SPSS Reliability Procedure (SPSS, 1990) to identify and eliminate possible items that were not contributing to an internally consistent description of the latent variables measured by the subscales in question.

Generally, the Cronbach alpha values are satisfactorily high for the transformational leadership subscales $(0,75<\alpha<$ $0,87)$, as they lie above the generally accepted value of 0,70 (Nunnally \& Marlowe, 1997).

High internal consistency was apparent for the items comprising the Altruism Scale $(\alpha=0,94)$ and the Integrity Scale $(\alpha=0,93)$. The subscales of the Ethical Climate Questionnaire also demonstrated satisfactory reliability $(0,77<\alpha<0,84)$.

Two items of the MLQ, one item of the Integrity Scale and two items of the ECQ were considered for possible elimination. Given the length of the subscales, the marginal increase in $\alpha$ affected by the removal of the items, and the magnitude of the item-total correlations, it was decided to retain the items.

\section{The relationship between altruism and transformational leadership}

Hypotheses 1 and 2 were tested by calculating a matrix of zero-order Pearson correlation coefficients. The convention proposed by Guilford (Tredoux \& Durheim, 2002:184) was used to interpret the sample correlation coefficients.

Hypothesis 1 suggested that altruism has a positive linear influence on transformational leadership. The results indicated a substantial $(r=0,63)$ and significant relationship $(\mathrm{p}<0,001)$ between altruism and transformational leadership (as measured by the total score on the MLQ). Hypothesis 1 was thus corroborated. Approximately $40 \%$ of the variance in transformational leadership could be statistically explained in terms of the variance in altruism. The finding implies that the more the leader is perceived to hold altruistic values the more his/her leadership tends to be perceived as transformational.

To further analyse the relationship between altruism and transformational leadership, the relationships with the dimensions of transformational leadership were examined. A substantial and significant relationship was found between altruism and intellectual stimulation $(\mathrm{r}=0,53$; $\mathrm{p}<0,001)$. This finding implies that altruistic leaders look out for the good in others, and that transformational leaders practising intellectual stimulation will openly bring about changes in their follower's values by the merit and relevance of their own ideas and mission, to the ultimate benefit and satisfaction of their followers (Bass \& Steidlmeier, 1999).

The results indicated a moderate and significant correlation between altruism and the idealised influence facet of 
transformational leadership ( $\mathrm{r}=0,65 ; \mathrm{p}<0,001)$. This means that idealised influence is manifested through altruistic behaviour that considers the needs of others over the leader's own personal needs, and avoids using power for personal gain (Bass \& Avolio, 1994).

The results showed a substantial and significant correlation between altruism and the inspirational motivation facet of transformational leadership $(\mathrm{r}=0,50 ; \mathrm{p}<0,001)$. This illustrates that the altruistic leader who practices inspirational motivation gets followers involved in the accomplishment of organisational goals by providing meaning and challenge in their work (Bass \& Avolio, 1994).

It was further found that there is a moderate and significant relationship between altruism and the individualised consideration facet of transformational leadership ( $\mathrm{r}=0,54$; $\mathrm{p}<0,001)$. Thus, the altruistic leader who practices individualised consideration takes the interests of others seriously and channels his or her need for power in socially constructive ways into the service of others (Bass \& Steidlmeier, 1998).

These findings support the research of Kanungo and Mendonca (1996) who argue that altruism is a crucial prerequisite for effective transformational leadership. In order to achieve exceptional levels of performance, the transformational leader should be perceived as sharing altruistic values (Engelbrecht, 2002). Effective transformational leadership thus is enabled by altruistic acts that reflect the leader's constant concern and desire to benefit others despite the risk of personal cost involved in such behaviour (Kanungo \& Mendonca, 1996).

\section{The relationship between transformational leadership and ethical climate}

Hypothesis 2 postulated that transformational leadership has a direct positive influence on ethical climate. The results indicated a fairly substantial $(\mathrm{r}=0,48)$ and significant relationship $(p<0,001)$ between transformational leadership and ethical climate (as measured by the total score on the ECQ). Hypothesis 2 thus survived the possibility of refutation. Approximately $23 \%$ of the variance in ethical climate could be explained in terms of the variance in transformational leadership.

To further analyse the relationship between transformational leadership and ethical climate, the relationships between the dimensions of these variables were examined. The results are indicated in Table 1, which shows that low to moderate and significant correlations were found between the dimensions of transformational leadership and the dimensions of ethical climate $(0,14<\mathrm{r}<0,49 ; \mathrm{p}<0,05)$. This implies that leaders who display intellectual stimulation, idealised influence, inspirational motivation and individualised consideration, will contribute to the development of the law and code climate, rules climate, independence climate and caring ethical climate in their work units.
Table 1: Pearson product-moment correlation between altruism, integrity, transformational leadership and ethical climate $(\mathbf{N}=200)$

\begin{tabular}{|c|c|c|c|c|}
\hline & $\begin{array}{l}\text { Intellectual } \\
\text { Stimulation }\end{array}$ & $\begin{array}{l}\text { Idealised } \\
\text { Influence }\end{array}$ & $\begin{array}{c}\text { Inspirational } \\
\text { Motivation }\end{array}$ & $\begin{array}{l}\text { Individualised } \\
\text { Consideration }\end{array}$ \\
\hline Altruism & $0,53 * *$ & $0,65 * *$ & $0,50 * *$ & $0,54 * *$ \\
\hline Integrity & $0,57 * *$ & $0,59 * *$ & $0,49 * *$ & $0,64 * *$ \\
\hline $\begin{array}{l}\text { Law and } \\
\text { Code }\end{array}$ & $0,30 * *$ & $0,32 * *$ & $0,33 * *$ & $0,22 * *$ \\
\hline $\begin{array}{l}\text { Rules } \\
\text { Climate }\end{array}$ & $0,24 * *$ & $0,26^{* *}$ & $0,22 * *$ & $0,14 *$ \\
\hline $\begin{array}{l}\text { Indepen- } \\
\text { dence }\end{array}$ & $0,15^{*}$ & $0,20 * *$ & $0,33 * *$ & $0,22 * *$ \\
\hline $\begin{array}{l}\text { Caring } \\
\text { Climate }\end{array}$ & $0,41^{* *}$ & $0,49 * *$ & $0,46^{* *}$ & $0,39 * *$ \\
\hline
\end{tabular}

The findings imply that the more unit leaders demonstrate transformational leadership, the stronger the ethical climate that exists in their units. This is consistent with the literature, which suggests that the transformational leadership style lends itself well to the creation of an ethical climate (Carlson \& Perrewe, 1995; Malan \& Smit, 2000; Yukl, 2002). This could be because the transformational leader as a role model of the behaviours required, reinforces ethical behaviour, and the followers follow this ethical example.

\section{The moderating effect of integrity on the relationship between transformational leadership and ethical climate}

Hypothesis 3 claimed that the interaction between integrity and transformational leadership would produce variance in the ethical climate that would not be attributable to the main effect of transformational leadership. A summary of the results of the hierarchical regression analysis is presented in Table 2.

Table 2: Regression of ethical climate on transformational leadership and the interaction between transformational leadership (TFL) and integrity

\begin{tabular}{l|r|c}
\hline \multicolumn{1}{c|}{ Predictor } & F & p \\
\hline Transformational Leadership & 59,652 & 0,00 \\
\hline TFL x Integrity & 4,039 & 0,046 \\
\hline $\mathrm{R}^{2}=0,244$ & & \\
\hline
\end{tabular}

Table 2 indicates that the interaction between transformational leadership and integrity, did significantly $(p<0,05)$ explain variance in ethical climate when included in a model that already contained the transformational leadership main effect. Hypothesis 3 was therefore confirmed. The transformational leadership-integrity interaction effect did explain unique ethical climate variance not explained by the leadership main effect. The regression model, however, explained only approximately $24 \%$ of the variance in ethical climate. The squared semi-partial correlation reveals that only approximately $1,5 \%\left(0,124^{2}\right)$ of the total variance in ethical climate could be explained in terms of the unique variance in the interaction effect not shared with the leadership main effect. 
The integrity scale was subsequently dichotomised to create a dummy variable (D-Integrity). The saturated regression model was used to test for coincidence in the regression of ethical climate on transformational leadership for the low and high integrity groups. The results of the standard multiple regression analysis is depicted in Table 3.

Table 3: Regression of ethical climate on transformational leadership, dichotomised integrity and the interaction between transformational leadership and dichotomised integrity

\begin{tabular}{l|r|r}
\hline \multicolumn{1}{c|}{ Predictor } & F & P \\
\hline Transformational Leadership & 22,093 & 0,000 \\
\hline Dichotomised integrity & 0,000 & 0,996 \\
\hline TFL x D-Integrity & 0,060 & 0,807 \\
\hline $\mathrm{R}^{2}=0.255$ & & \\
\hline
\end{tabular}

From Table 3, it is clear that the addition of the dichotomised integrity main effect and the interaction effect to a model already containing the leadership main effect did not significantly $(p>0,05)$ explain additional variance in ethical climate. It could thus be concluded that the regression of ethical climate on transformational leadership does not significantly differ in intercept and/or slope between leaders with relatively low and high levels of integrity. The regression of ethical climate on transformational leadership thus coincides for the low and high integrity groups, as depicted in Figure 2.

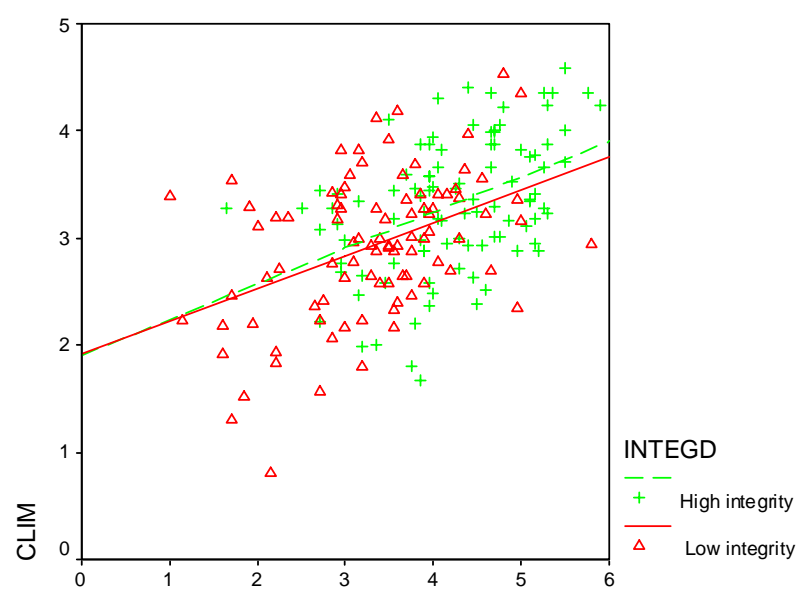

LEAD

Figure 2: Regression of ethical climate on transformational leadership for low and high integrity leaders separately

The ability to account for the variance in ethical climate in terms of transformational leadership was therefore not improved by allowing for different slopes in the regression of ethical climate on transformational leadership for different levels of integrity. In terms of the present analysis, no convincing support was thus found for the hypothesis that the extent to which transformational leadership would affect ethical climate would depend on the extent to which the leader demonstrated integrity.
Projecting the data points in Figure 2 on the X-axis did, however, reveal that leaders that display high integrity tend to demonstrate more transformational leadership competencies than leaders with low integrity. Table 4 indicates that the difference is significant and that integrity accounted for approximately $22 \%$ of the variance in transformational leadership.

Table 4: Univariate analysis of variance on the significance of differences in transformational leadership across integrity groups

\begin{tabular}{l|c}
\hline \multicolumn{1}{c|}{ Groups } & TFL Mean \\
\hline Low Integrity & 3,305 \\
\hline High Integrity & 4,235 \\
\hline $\mathrm{F}=52,726$ & \\
$\mathrm{p}=0,000$ & \\
$\mathrm{R}^{2}=0,218$ & \\
\hline
\end{tabular}

Although the initial model (see Figure 1) only made provision for an altruism main effect on transformational leadership, the foregoing finding begs the question whether integrity would significantly explain variance in transformational leadership when included in a model already containing altruism. Table 5 reveals that both integrity and altruism significantly explain unique variance in transformational leadership. Approximately $50 \%$ of the variance in transformational leadership could be explained in terms of the weighted linear composite of these two predictors. Table 5, moreover, indicates that approximately $18 \%\left(0,420^{2}\right)$ of the variance in transformational leadership, not accounted for by altruism, could be explained in terms of the unique variance in integrity.

Table 5: Regression of transformational leadership on altruism and integrity

\begin{tabular}{l|c|c|c}
\hline \multicolumn{1}{c|}{ Predictor } & t & p & Partial \\
\hline Altruism & 8,221 & 0,000 & 0,505 \\
\hline Integrity & 6,503 & 0,000 & 0,420 \\
\hline $\mathrm{F}=99,603$ & & & \\
$\mathrm{p}=0,000$ & & & \\
$\mathrm{R}^{2}=0,503$ & & & \\
\hline
\end{tabular}

Table 5, in addition, revealed that, of the two independent variables included in the model, altruism was the more influential predictor of transformational leadership. This was indicated by the larger standardised regression coefficient associated with altruism and the larger proportion of unique variance explained in leadership when holding integrity constant in both the criterion and the predictor $\left(0,505^{2}\right)$. This finding is in agreement with the generally held view in the literature that altruism is a primary ethical value of transformational leadership (Ciulla, 1996; Engelbrecht, 2002; Kanungo \& Mendonca, 1996; Malan \& Smit, 2000).

The argument presented thus far contended that the extent to which transformational leadership would affect ethical climate would depend on the degree to which the leader demonstrated integrity. The hypothesis thus stated that leadership integrity moderated the effect of leadership on 
ethical climate. No convincing empirical support for this position could be found.

The foregoing findings seem to suggest that integrity should still be viewed as a prerequisite for establishing ethical climate via leadership, but possibly through operating in a different fashion than initially proposed. However, the results seem to suggest that the more leaders demonstrate integrity in that they show consistency and reveal coherence among what they believe, how they lead, and the type of organisations they want to build, the more their followers will tend to perceive them as transformational leaders. Transformational leadership, in turn, positively influences the ethical climate existing in a work unit.

\section{Conclusions}

This study analysed the relationship between altruism and transformational leadership, transformational leadership and ethical climate, and the moderating effect of integrity on the relationship between transformational leadership and ethical climate. The goal of this study was to investigate the different theoretical relationships between ethical values, leadership and ethical climate in the South African context (see Figure 1).

Various insights have been gained as a result of a comprehensive series of statistical analyses that underlie this study. The principal component analyses ensured unidimensionality on all subscales of the questionnaire. In this process, the items of both the integrity subscale and the caring climate subscale evidently loaded on two orthogonal factors, but it was decided to leave the items as they were, due to the length of the scales. Item analyses furthermore demonstrated satisfactory internal consistency for all subscales used to measure latent variables.

Although this study did not convincingly confirm the hypothesised relationships between transformational leadership, integrity and ethical climate, important insight was gained into the direct role transformational leaders play in the development of an ethical climate. Another contribution was the positive role of ethical values in transformational leadership. The positive effect of altruism and integrity on transformational leadership revealed that leaders would only be perceived as transformational if they were driven by altruistic motives and actions, and if they displayed consistency in words and actions.

The positive relationship between transformational leadership and ethical climate emphasises the importance of transformational leadership behaviour when leaders and ethical organisations are being developed. Transformational leaders can make a significant impact on the ethical performance of organisations. The literature study has suggested that the leader is responsible for the set of ethics or norms that governs the conduct of people in the organisation (Kouzes \& Posner, 1999) and that it is vital that the work climate of the organisation encourage ethical behaviour. In order to create and develop ethical leaders, top management must be committed to a clear code of ethical conduct; recruit, select, and promote leaders with core ethical values; develop performance standards that reward ethical behaviour; and encourage training in ethical leadership skills (Carlson \& Perrewe, 1998; Van Niekerk, 2003; Yukl, 2002). The data analyses have confirmed this, and leaders who wish to build ethical organisations should take cognisance of the influence that their behaviour exerts on ethical work climates.

To validate the full theoretical model that underlies this study, it is recommended that an in-depth study be undertaken of the other ethical values displayed by ethical leaders (e.g. Engelbrecht, 2001), to explore their effect on ethical climate. The hypothesised moderating effect of ethical climate on the relationship between transformational leadership and unit performance should be tested empirically in subsequent studies. Alternative structural models for explaining the role of integrity in leadership should also be tested.

Understanding the consequences of ethical climates should prompt the design of intervention strategies to change climates, and evaluation research to assess change strategies, for instance to determine whether ethical training programmes actually improve the ethical behaviour of employees (Van Niekerk, 2003).

The role of servant leadership (Yukl, 2002) in the development of an ethical climate should also be explored in future studies, since servant leaders approach leadership from a strong moral standpoint.

This study makes a valuable contribution to theory building and practice in the field of organisational psychology, especially in the South African context, due to the problem of escalating unethical behaviour within South African organisations. The fact that South Africa is part of the global village defines the rules of competent and ethical leadership (Malan \& Smit, 2001). This means that leaders, as creators and sustainers of competence and morality, must assume the courage to be authentic ethical role models. From this study, it is clear that understanding the leader behaviours that contribute to the development of an ethical climate will be part of the solution to the problem of unethical practices in organisations.

\section{References}

Bass, B.M. \& Avolio, B.J. 1994. Improving organizational effectiveness through transformational leadership. Thousand Oaks: SAGE Publications.

Bass, B.M. \& Avolio, B.J. 1995. The multifactor leadership questionnaire (Form 5-45). Palo Alto, CA: Consulting Psychologist Press.

Bass, B.M. \& Steidlmeier P. 1999. 'Ethics, character, and authentic transformational leadership behavior,' Leadership Quarterly, 10(2):181-217.

Badaracco, J.L. \& Ellsworth, R.R. 1991. Leadership and the quest for integrity. Boston: Harvard Business School Press.

Berenson, M.L., Levine, D.M. \& Goldstein, M. 1983. Intermediate statistical methods and applications; a 
computer package approach. Englewood Cliffs, New Jersey: Prentice Hall.

Carlson, D.S. \& Perrewe, P.L. 1995. 'Institutionalisation of organisational ethics through transformational leadership,' Journal of Business Ethics, 14(10):828-838.

Ciulla, J.B. 1996. Ethics, the heart of leadership. Westport, CT: Praeger Publishers.

Cohen, D.V. 1993. 'Creating and maintaining ethical work climates: Anomie in the workplace and implications for managing change,' Business Ethics Quarterly,3(4):343-358.

Craig, S.B. \& Gustafson, S.B. 1998. 'Perceived leader integrity scale: An instrument for assessing employee perceptions of leader integrity,' Leadership Quarterly, 9(2):127-145.

Dickson, M.W., Smith, D.B., Grojean, M.W. \& Ehrhart, M. 2001. 'An organisational climate regarding ethics: The outcome of leader values and the practices that reflect them,' Leadership Quarterly, 12(2):197-218.

Engelbrecht, A.S. 2001. 'Core values underlying transformational and transactional leadership,' Management Dynamics, 10(3):56-80.

Engelbrecht, A.S. 2002. 'The effect of organisational leadership on value congruence and effectiveness: An integrated model,' South African Journal of Economic \& Management Sciences, 5(3):589-606.

Engelbrecht, A.S. \& Cloete, B.E. 2000. 'An analysis of a supervisor-subordinate trust relationship,' Journal of Industrial Psychology, 26(1):24-28.

Hesselbein, F., Goldsmith, M. \& Beckhard, R. 1996. The leader of the future. San Francisco: Jossey-Bass Publishers.

Jöreskog, K. \& Sörbom, D. 1996. LISREL 8: User's reference guide. Chicago, IL: Scientific Software International, Inc.

Kanungo, R.N. \& Mendonca, M. 1996. Ethical dimensions of leadership. Thousand Oaks: SAGE Publications.

Kouzes, J.M. \& Posner, B.Z. 1999. Encouraging the heart. San Francisco: Jossey-Bass.

Krafft, P., Engelbrecht, A.S. \& Theron, C.C. 2004. 'The influence of transformational and transactional leadership on dyadic trust relationships through perceptions of fairness,' South African Journal of Industrial Psychology, 30(1):1826.

Langley, R. 1992. Values scale. Pretoria: Human Science Research Council.

Lowe, K.B., Kroeck, K.G. \& Sivasubramaniam, N. 1996. 'Effectiveness correlates of transformational and transactional leadership: A meta-analytic review of the MLQ literature,' Leadership Quarterly, 7(3):385-426.
Malan, F. \& Smit, B. 2001. Ethics and leadership in business and politics. Cape Town: Juta \& Co.

Matthews, M.C. 1987. 'Codes of Ethics: Organisational behaviour and misbehaviour'. In Frederick, W.C. \& Preston, L.E. (Eds.). Research in corporate social performance and policy. Greenwich: Jai Press Inc.

McFall, L. 1987. 'Integrity,' Ethics, 98(1): 5-20.

Montefiore, A. \& Vines, D. 1999. Integrity in the public and private domains. London: Routledge.

Nunnally, R.C. \& Marlowe, H.A. 1997. Psychometric theory. New York: McGraw Hill.

Parry, K.W. \& Proctor-Thomson, S.B. 2002. 'Perceived integrity of transformational leaders in organisational settings,' Journal of Business Ethics, 35:75-96.

Rossouw, G.J. 1997. 'Business ethics in South Africa,' Journal of Business Ethics, 16:1539-1547.

Schminke, M. 1998. Managerial ethics. New Jersey: Lawrence Erlbaum Associates, Publishers.

Sims, R.R. 1994. Ethics and organisational decisionmaking. Connecticut: Quorum Books.

SPSS. 1990. SPSS reference guide. Chicago, Illinois: SPSS International.

Tredoux, C.T. \& Durheim, K. 2002. Numbers, hypotheses and conclusions: A course in statistics for the social sciences. Cape Town: UCT Press.

Trevino, L.K, Hartman, L.P. \& Brown, M. 2000. 'Moral person and moral manager: How executives develop a reputation for ethical leadership,' California Management Review, 42(4):128-147.

Van Niekerk, A.A. 2003. 'Can more business ethics teaching halt corruption in companies?' South African Journal of Philosophy, 22(2):128-138.

Victor, B. \& Cullen, J.B. 1987. 'A theory and measure of ethical climate in organisations'. In Frederick, W.C. \& Preston, L.E. (Eds.). Research in corporate social performance and policy. Greenwich: Jai Press Inc.

Victor, B. \& Cullen, J.B. 1988. 'The organisational bases of ethical work climates,' Administrative Science Quarterly, 3(1):101-125.

Weber, J. 1995. 'Influences upon organisational ethical subclimates: A multi-departmental analysis of a single firm,' Organization Science, 6(5):509-523.

Yukl, G. 2002. Leadership in organisations. Upper Saddle River, NJ: Prentice-Hall. 